\title{
Modelling of the Water Absorption Kinetics and Determination of the Water Diffusion Coefficient in the Pith of Raffia vinifera of Bandjoun, Cameroon
}

\author{
E. Tiaya Mbou, ${ }^{1,2}$ E. Njeugna, ${ }^{1,2}$ A. Kemajou, ${ }^{2}$ N. R. Tagne Sikame, ${ }^{1}$ and D. Ndapeu ${ }^{1}$ \\ ${ }^{1}$ Mechanical Laboratory and Adapted Materials (LAMMA) ENSET, University of Douala, P.O. Box 1872, Douala, Cameroon \\ ${ }^{2}$ Laboratory of Energetic (LE) Unit for Physical Doctoral Formation and Engineering Science, University of Douala, Douala, Cameroon
}

Correspondence should be addressed to E. Tiaya Mbou; elvistiaya@yahoo.fr and E. Njeugna; njeugna@yahoo.fr

Received 2 August 2016; Accepted 14 December 2016; Published 13 February 2017

Academic Editor: Belal F. Yousif

Copyright ( $\odot 2017$ E. Tiaya Mbou et al. This is an open access article distributed under the Creative Commons Attribution License, which permits unrestricted use, distribution, and reproduction in any medium, provided the original work is properly cited.

\begin{abstract}
The present work focuses on the study of the water absorption phenomenon through the pith of Raffia vinifera along the stem. The water absorption kinetics was studied experimentally by the gravimetric method with the discontinuous control of the sampling mass at temperature of $30^{\circ} \mathrm{C}$. The samples of $70 \mathrm{~mm} \times 8 \mathrm{~mm} \times 4 \mathrm{~mm}$ were taken from twelve sampling zones of the stem of Raffia vinifera. The result shows that the percentage of water absorption of the pith of Raffia vinifera increases from the periphery to the center in the radial position and from the base to the leaves in the longitudinal position. Fick's second law was adopted for the study of the water diffusion. Eleven models were tested for the modelling of the water absorption kinetics and the model of Sikame Tagne (2014) is the optimal model. The diffusion coefficients of two stages were determined by the solution of the Fick equation in the twelve sampling zones described by Sikame Tagne et al. (2014). The diffusion coefficients decreased from the center to the periphery in the radial position and from the base to the leaves in the longitudinal position.
\end{abstract}

\section{Introduction}

The raffia is a plant which is found in the tropical zones particularly in Madagascar and which is generally grown in the swampy zone $[1,2]$. In the world, there are about twenty (20) species among which the Raffia vinifera is found in the West, the Northwest, the South, the Center and the East Regions of Cameroon. This raffia is constituted with a feather grass bearing stick with stout rachis and large petiole $[2,3]$.

Raffia is generally used in the realization of arts, crafts, decoration, braces, clothes, baskets, hats, beds, and food (sap/wine) [1,4]. Raffia is also used in the West Region of Cameroon as a building material specially as ceiling material, but this use is still local. Our main objective is to extend the use of raffia as ceiling material over the world particularly in our country. The pith of raffia will be combined with another material, such as polymer and other vegetal material, to produce a new composite building material suitable for ceiling applications. The physical behavior of our pith of Raffia vinifera has to be known because the realization of the composite material will use the matrix, which is liquid and will be absorbed by our pith of raffia. It is important in our study to know the water diffusion coefficient and the percentage of the water absorption that will help us to predict the behavior of the composite material.

Several works have been carried out on the raffia such as the study of the thermal properties on trunk of Raffia hookeri which is used as ceiling material [5]. Some studies are also carried out on the study and the use of raffia and other vegetal products as insulation material in Cameroon [6]. Other works include the use of raffia in the reinforcement of concrete [7]. The use of raffia in the textile industry is equally growing. Studies are also carried out on the study of the microstructure and the physical properties of fibers coming from the leaves of raffia; the drying kinetics of these fibers is carried in view of its use as roofing elements $[8,9]$. Mechanical studies have been carried out on the long-term creep behavior of the Raffia vinifera stem in compression and flexion tests [10-13]. A study on the long-term mechanical behavior and the mechanical properties of fibers from the 


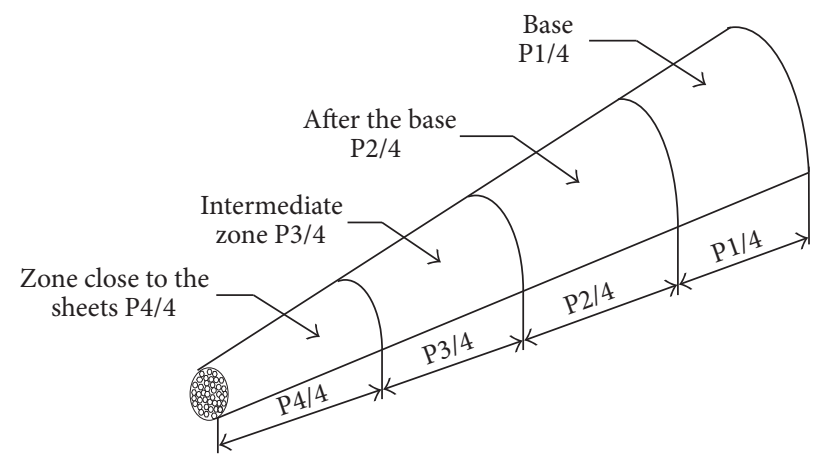

(a)

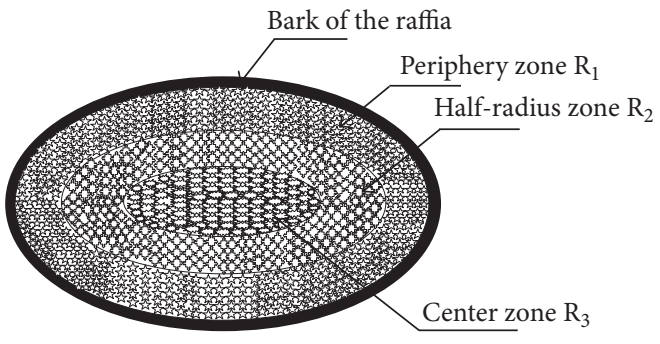

(b)

FIGURE 1: Localization of the sampling zone on the stem of raffia. (a) Longitudinal position and (b) radial position corresponding to each longitudinal position $[1,4,15]$.

Raffia vinifera has been done [4]. Studies have been equally done on the traction and compression of composite cement matrix reinforcement by the raffia fiber [14].

In the same vein and in the view of improving the scientific knowledge so as to optimize the use of Raffia vinifera, this study focuses on the study of the water absorption phenomenon in the Raffia vinifera pith. The main objective of this work is to evaluate the percentage of the water absorbed, do the modelling of the water absorption kinetics, and evaluate the diffusion coefficient of water through the pith of Raffia vinifera.

In this article, we analyzed the distribution of water absorption rate of our material through the stem of raffia respectively on the sampling zones described by Sikame Tagne et al. [4]. The modelling of the water absorption kinetics is also taken in place. The diffusion coefficient of water through the material was evaluated in the sampling zones and followed by the conclusion.

\section{Methods}

2.1. Materials. The samples used in this work come from the stem of Raffia vinifera originating from Bandjoun in the West Region of Cameroon particularly the Koung-Khi division. In the stem, prismatic samples are cut particularly on the parallelepiped shape with $70 \mathrm{~mm} \times 8 \mathrm{~mm} \times 4 \mathrm{~mm} \pm 1 \mathrm{~mm}$. The largest dimension of the sample is along the length of the stem. The samples were taken from the twelve sampling zones described by Sikame Tagne et al. [4] and presented in Figure 1. In the stem, we distinguished four parts (Figure 1(a)) from the bottom to the top named P1/4 (near the root), P2/4, $\mathrm{P} 3 / 4$, and $\mathrm{P} 4 / 4$ (near the leaves). In the radial position, we distinguished three zones (Figure 1(b)) called center, halfradius, and periphery (near the bark) zones.

A microwave of Bosch mark was used as oven for the drying of the sample at a constant temperature until the mass is stabilized. Digital scales of ADAM mark with a maximum weight of $750 \mathrm{~g}$ and to the milligram accuracy level are used for the various weighing. A numerical slide caliper with the hundredth of the millimeter accuracy is used for the measurement of the sample dimensions. The distilled water at the ambient temperature of $30^{\circ} \mathrm{C} \pm 1^{\circ} \mathrm{C}$ is used for the immersion of the samples as in the case of the absorption of other types of wood such as Afra, Ojamlesh, and Roosi $[1,16,17,28]$.

2.2. Methods. The section of the stem of raffia has an elliptic form. The large diameter of the raffia stem is about $62 \mathrm{~mm}$ on the base, $40 \mathrm{~mm}$ on the middle, and $34 \mathrm{~mm}$ on the top. The small diameter of the raffia stem is about $51 \mathrm{~mm}$ on the base, $36 \mathrm{~mm}$ on the middle, and $29 \mathrm{~mm}$ on the top. After subdivision of the stem in four parts named $\mathrm{P} 1 / 4, \mathrm{P} 2 / 4, \mathrm{P} 3 / 4$, and $\mathrm{P} 4 / 4$, we removed the bark of each part. According to each longitudinal position, the remaining diameter was divided into three parts to obtain primary samples following radial position (center, half-radius, and periphery zones). On this primary samples, we extracted the final samples which have a parallelepiped shape with the following dimensions $70 \mathrm{~mm} \times 8 \mathrm{~mm} \times 4 \mathrm{~mm}$. The samples were extracted in the twelve sampling zones on the stem.

The obtained samples are now conditioned in the microwave used as the oven at the constant temperature of $90^{\circ} \mathrm{C}$ until stabilization of the mass. This gravimetric analysis method is done in order to eliminate residual water found in the samples. The samples were then introduced in plastic bags to avoid reabsorption of moisture from the air during the samples cooling period. Conditioned samples are weighed and labeled before being introduced into the distilled water. After the drying phase, we introduced our samples in the distilled water at the laboratory room temperature estimated at $30^{\circ} \mathrm{C} \pm 1^{\circ} \mathrm{C}$. The samples are maintained under water by nuts made of rustproof steel. During the regular time intervals, samples were removed from the water; surface water of the sample was then eliminated with a dry fabric base on cotton and the samples were weighted and reintroduced into the distilled water. This operation was done in very short time so as to enable us to neglect the time that was spent out of the distilled water. At the beginning of the test, immersion time is taken at five minutes. After one hour of test, we changed it to ten minutes. We prolonged the weight time until we arrive at weight one time per day, one time after two days, three days, and eventually one time per week. The process of 
weighting is repeated until the constant mass, that is, until samples reach water saturation level [16, 29-32].

In each sampling zone, twenty (20) samples were tested for a total of two hundred and forty (240) samples of Raffia vinifera along the stem. These samples were extracted from two dry mature stems of Raffia vinifera for each zone. These samples were mixed and tested in the group. The test was stopped when the mass no longer varies.

The statistical analysis of experimental data was done in the Matlab 2009b software environment which enabled drawing experimental curves and doing the modelling with different models as found in Table 4 . The best model was the one which has an average correlation coefficient near to the unit, the square root of mean error average near zero, and the sum of square error average near zero. These two last statistical parameters are defined by the following $[1,26]$ :

$$
\begin{aligned}
\mathrm{RMSE} & =\sqrt{\frac{\sum_{i=1}^{n}\left(m_{c i}-m_{e i}\right)^{2}}{n},} \\
\mathrm{SSE} & =\sum_{i=1}^{n}\left(m_{c i}-m_{e i}\right),
\end{aligned}
$$

where $m_{c i}, m_{e i}$, and $n$ are the theoretical mass, the predicted mass, and the number of observation, respectively.

2.2.1. Mass Diffusion Theory through Solid. The mass transfer equation of solid result from the second Fick law given by

$$
\frac{\partial C}{\partial t}=\operatorname{div}(\overrightarrow{D \operatorname{grad} C})
$$

where $C$ is the molar concentration $\left(\mathrm{mol} / \mathrm{m}^{3}\right), D$ is the diffusion coefficient $\left(\mathrm{m}^{2} / \mathrm{s}\right)$, and $t$ is the time $(\mathrm{s})$.

To simplify the resolution of (2), it is supposed that the diffusion coefficient is independent of the space direction [33, 34]. This hypothesis enables us to write (2) in the following form:

$$
\frac{\partial C}{\partial t}=D\left(\frac{\partial^{2} C}{\partial x^{2}}+\frac{\partial^{2} C}{\partial y^{2}}+\frac{\partial^{2} C}{\partial z^{2}}\right)
$$

It is assumed that the sample is the plane shape and it is assumed to have a single long direction, the $z$ direction in Figure 2(b), so that the diffusion equation can be solved in one dimension across the shortest dimension of the sample. In our case, the $x$ direction is the one on which diffusion has taken place. Figure 2 presents the samples obtained for the test (Figure 2(a)) and the plan which presents the dimensions of the sample (Figures 2(b) and 2(c)). These hypotheses enabled the reduction of (3) which then gives $[29,33,34]$

$$
\frac{\partial C}{\partial t}=D \frac{\partial^{2} C}{\partial x^{2}}
$$

By taking into account the boundary's conditions, we have

$$
\begin{aligned}
& C=C_{0}, \\
& 0<x<L, \\
& t=t_{0}, \\
& C=C_{1},
\end{aligned}
$$

where $L$ is the thickness of the sample.

The solution of (4) can be given in the following form:

$$
\begin{aligned}
& \frac{C-C_{0}}{C_{1}-C_{0}}=1-\frac{4}{\pi} \sum_{n=0}^{\infty} \frac{(-1)^{n}}{2 n+1} \exp \left\{-\frac{D(2 n+1)^{2} \pi^{2} t}{4 L^{2}}\right\} \\
& \cdot \cos \left(\frac{(2 n+1) \pi x}{2 L}\right) .
\end{aligned}
$$

If we call $M_{t}$ the total mass of water which diffuses in the material at $t$ instant and $M_{\infty}$, the same quantity at the infinite time, that is to say, when the saturation of the material is reached, then $[23,25,29,35]$ (6) can be written in the following form:

$$
\begin{aligned}
\frac{M_{t}}{M_{\infty}}= & 1 \\
& \quad-\sum_{n=0}^{\infty} \frac{8}{(2 n+1)^{2} \pi^{2}} \exp \left(-\frac{D_{\mathrm{eff}}(2 n+1)^{2} \pi^{2} t}{4 L^{2}}\right) .
\end{aligned}
$$

2.2.2. Percentage of Water Absorption. The percentage of water absorption of our sample (WA) is given by the following relation, which was also used for the determination of the water absorption by $[15,16,36]$

$$
\mathrm{WA}=\frac{m_{f}-m_{i}}{m_{i}} * 100,
$$

where $m_{f}$ and $m_{i}$ are, respectively, the final and initial mass of the sample.

2.2.3. Study of the Absorption Kinetics. The ratio of the water absorption called $g(t)$ is defined as follows:

$$
g(t)=\frac{M_{t}}{M_{\infty}}=\frac{m_{t}-m_{0}}{m_{\infty}-m_{0}} .
$$

The similarity between (7) and (9) enables us to write

$$
\begin{aligned}
g(t) & =\frac{M_{t}}{M_{\infty}}=\frac{m_{t}-m_{0}}{m_{\infty}-m_{0}} \\
& =1-\sum_{n=0}^{\infty} \frac{8}{(2 n+1)^{2} \pi^{2}} \exp \left(-\frac{D_{\mathrm{eff}}(2 n+1)^{2} \pi^{2} t}{4 L^{2}}\right),
\end{aligned}
$$

where $m_{0}, m_{t}$, and $m_{\infty}$ are, respectively, the anhydrous mass (at the initial instant), at current moment and at the infinite time $(t=\infty)$, that is, at saturation. 


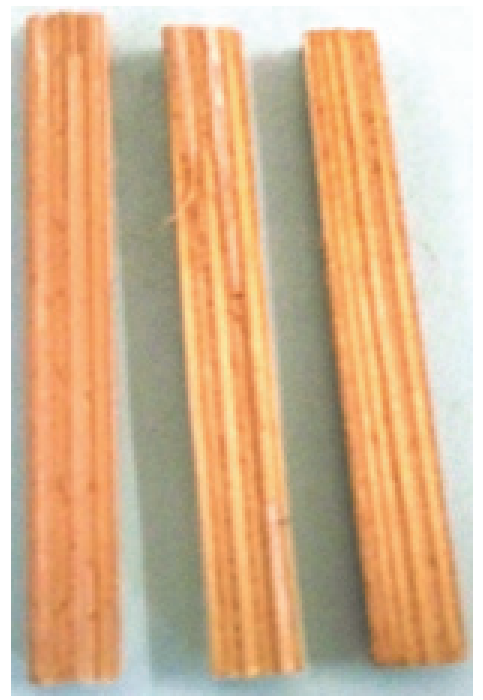

(a)

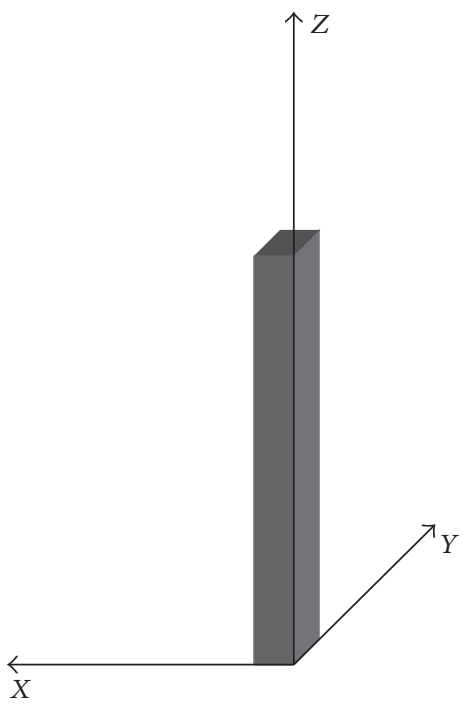

(b)
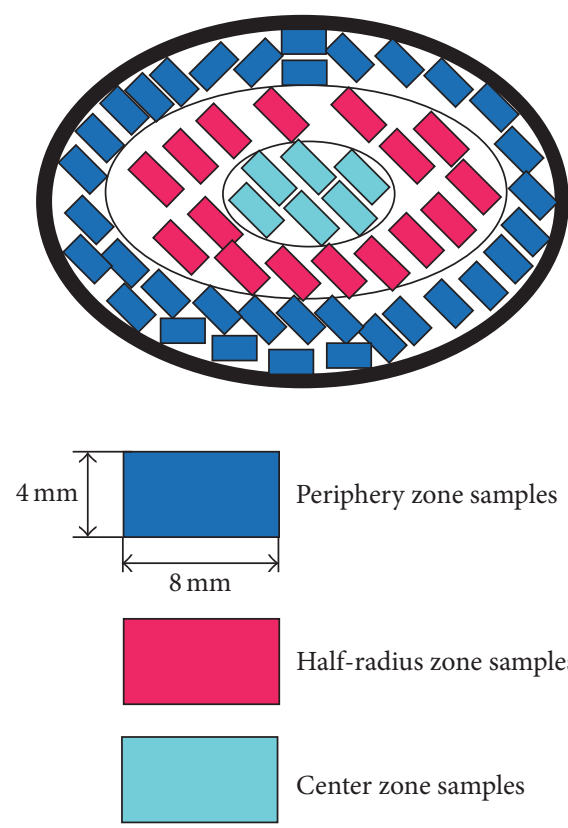

Half-radius zone samples

Center zone samples

(c)

FIGURE 2: Illustration of the samples used for the test. (a) Picture of the sample, (b) axis orientation of the sample, and (c) extraction zone of the samples in the radial position.

\section{Results and Discussions}

3.1. Determination of the Percentage of Water Absorption. The percentage of water absorption of our samples for the twelve sampling zones is done by (8). The synthesis result is presented in Table 1.

It is observed that the average percentage of water absorption stands between $392.044 \% \pm 36.618 \%$ and $1331.956 \% \pm$ $49.144 \%$ during the immersion period estimated at 45 days.

A comparative study of the percentage of the water absorption of the Raffia vinifera pith and other vegetal products has been done, in Table 2. This study indicates that the Raffia vinifera pith absorbs more water than the fibers taken in the same position of the stem [4]. This is probably due to the fact that the samples of pith of Raffia vinifera are the natural composites materials comprising fibers and a spongy part that work as a natural binder between the fibers and which in addition absorbs water.

The average of the percentage of water absorption along the stem is presented on Figure 3. Globally the observation of Figure 3 enables us to see that the percentage of water absorption increases from the periphery to the center on the radial position and from the base to the leaves on the longitudinal position along the stem of Raffia vinifera.

3.2. Kinetics of Water Absorption. Equation (9) allows us to plot the curve of water absorption ratio according to the time and the obtained curve is presented by Figure 4 . This curve presents the results of water absorption test of the pith of Raffia vinifera taken from the center of part 4/4.

The obtained curves on the twelve sampling zones have the same profile as that presented in Figure 4.

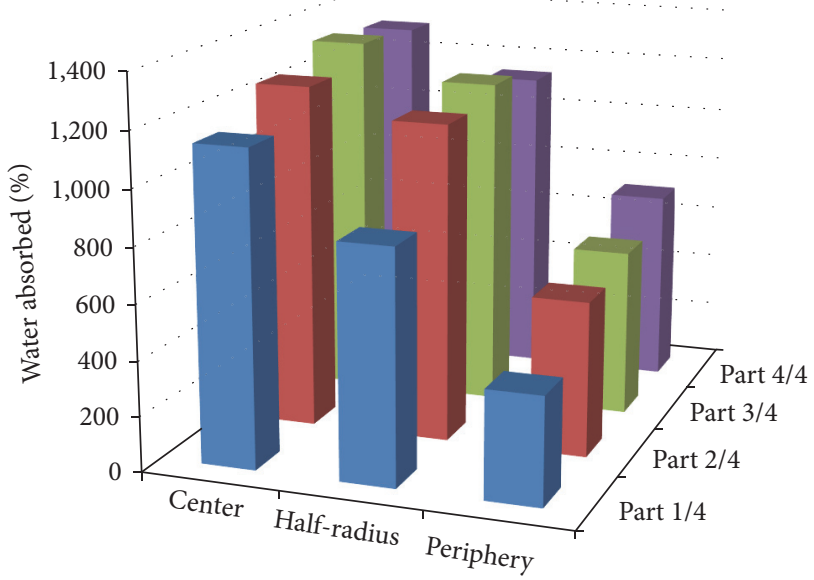

FIGURE 3: Distribution of the water absorption rate percentage of the pith of Raffia vinifera.

An observation of the curve presented in Figure 4 shows that, during the first 5000 minutes, approximately $50 \%$ of the sample masses reached saturation level.

The curve presented in Figure 4 is similar to the curve obtained by other authors who have studied water absorption kinetics in natural materials [4, 16, 26, 27, 34, 37]. It was noticed that the water absorption kinetics of the pith of Raffia vinifera takes place in two phases: the first phase rapidly takes place and enables reaching approximately $50 \%$ of the mass at saturation. This is done in the first 5000 minutes and the second phase that is relatively slow and is represented by the second part of the curve. This brings out two diffusion 
TABLE 1: Average rate of water absorption and standard deviation of the Raffia vinifera pith.

\begin{tabular}{lccr}
\hline & Center & Half-radius & Periphery \\
\hline Part $1 / 4$ & $\mathbf{1 1 4 1 . 5 0 9} \pm 156.063$ & $\mathbf{8 4 7 . 5 2 5} \pm 95.568$ & $\mathbf{3 9 2 . 0 4 4} \pm 36.618$ \\
Part $2 / 4$ & $\mathbf{1 2 5 6 . 6 9 6} \pm 87.415$ & $\mathbf{1 1 5 6 . 7 0 5} \pm 79.810$ & $\mathbf{5 6 5 . 9 6 7} \pm 100.128$ \\
Part 3/4 & $\mathbf{1 3 3 1 . 9 5 6 \pm 4 9 . 1 4 4}$ & $\mathbf{1 2 0 7 . 1 3 3} \pm 107.053$ & $\mathbf{6 1 2 . 1 9 8} \pm 132.146$ \\
Part $4 / 4$ & $\mathbf{1 3 0 8 . 6 7 7} \pm 53.766$ & $\mathbf{1 1 3 7 . 9 3 2} \pm 61.979$ & $\mathbf{7 0 5 . 0 1 8} \pm 113.600$ \\
\hline
\end{tabular}

TABLE 2: Comparison of the percentage of water absorption of the pith of Raffia vinifera with other natural materials.

\begin{tabular}{|c|c|c|c|c|}
\hline Types & Percentage of water absorbed (\%) & Absorption duration & Temperature $\left({ }^{\circ} \mathrm{C}\right)$ & References \\
\hline Afra wood & 102 & & & \\
\hline Ojamlesh Wood & 54 & 25 Days & 25 & {$[16]$} \\
\hline Roosi Wood & 120 & & & \\
\hline Hemp & 62 & & & \\
\hline Okra & 64 & 13 Days & $27-67$ & [17] \\
\hline Betel nut & 38 & & & \\
\hline Fibers of Raffia vinifera & $303-662$ & 25 Days & 23 & {$[4]$} \\
\hline Pith of the Raffia vinifera & $392-1331$ & 45 Days & $30 \pm 1$ & Studied case \\
\hline
\end{tabular}

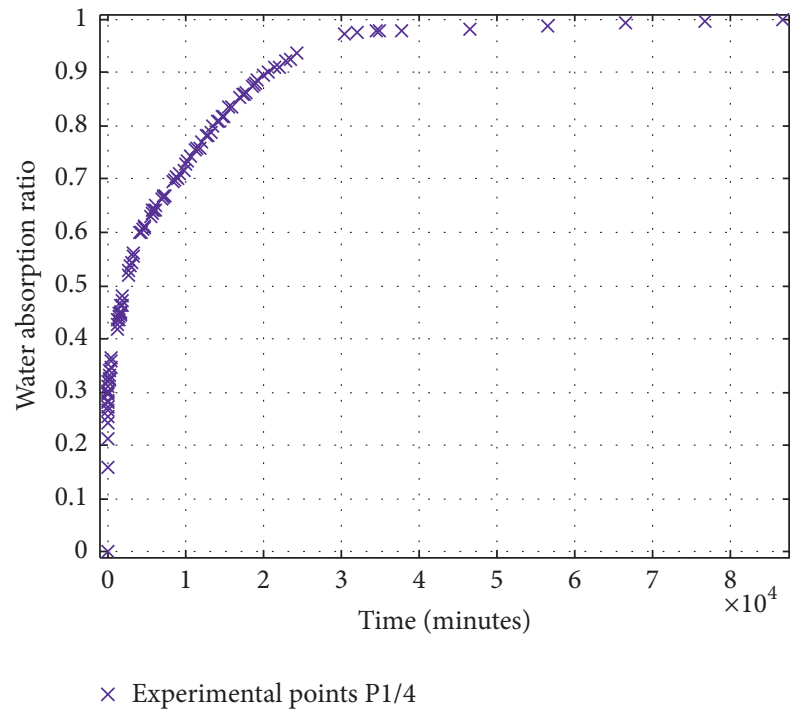

FIgURE 4: Average of the water absorption kinetics of the pith of Raffia vinifera from the center and at the base of the stem (1/4).

coefficients which indicate the velocity of the water diffusion in the pith of Raffia vinifera samples.

3.3. Modelling of the Water Absorption Kinetics. The water absorption kinetics in the pith of Raffia vinifera is done by using the mathematical models found in the literature. In this fact, we found eleven models which are in Table 3.

The experimental data of the pith of Raffia vinifera of the center from the base of the stem and the eleven models found in the literature are represented in the Figure 5.

Table 4 provides a summary of the parameters of the various models previously cited concerning samples of the pith coming from part 1/4 of the Raffia vinifera stem.

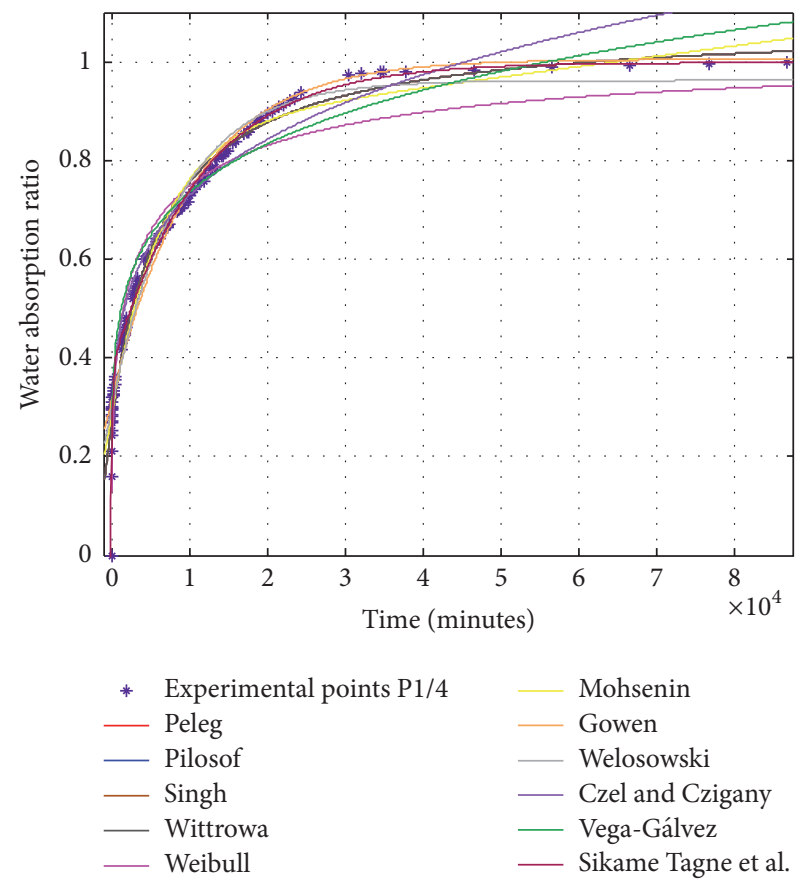

FIGURE 5: Experimental curve of the pith of Raffia vinifera and curves of models.

The variations presented by some models such as those by Singh and Kulshrestha (1987) and Pilosof et al. (1987) can be interpreted by the fact that these models are not ideal to describe the kinetics of water absorption of the pith of Raffia vinifera.

According to Table 4, it can be seen that the models used in this work have the coefficients of correlation higher than 0.93. In the case of this work the model of Weibull has the lowest correlation coefficient. The better model is the model of Sikame Tagne et al. which has the correlation coefficient 
TABLE 3: Utilized models summary for the modelling of the absorption kinetics.

\begin{tabular}{|c|c|c|c|}
\hline Number & Model's name & Model's equation & References \\
\hline 1 & Pilosof & $g(t)=a+\frac{b * t}{c+t}$ & {$[18]$} \\
\hline 2 & Mohsenin & $g(t)=a *[1-\exp (-k * t)]+c+d * t$ & {$[16,19]$} \\
\hline 3 & Singh & $g(t)=a+\frac{b * t}{c * t+1}$ & {$[20]$} \\
\hline 4 & Peleg & $g(t)=a+\frac{t}{b * t+c}$ & {$[21,22]$} \\
\hline 5 & García-Pascual & $g(t)=1-\exp \left[-\left(\frac{t}{a}\right)^{b}\right]$ & {$[23]$} \\
\hline 6 & Gowen & $g(t)=(a-b) * \exp (-k * t)+b$ & {$[24]$} \\
\hline 7 & Czel and Czigany & $g(t)=a * t^{m}$ & {$[25]$} \\
\hline 8 & Vega-Gálvez & $g(t)=a * \exp \left(-\frac{b}{(1+t)^{\alpha}}\right)$ & {$[26]$} \\
\hline 9 & Gornicki & $g(t)=a *(b-\exp (-k * t))$ & {$[27]$} \\
\hline 10 & Gornicki & $g(t)=a+b *\left(1-\frac{1}{1+b * c * t}\right)$ & {$[27]$} \\
\hline 11 & Sikame Tagne & $g(t)=c-a * \exp (-k * t)-b * \exp (-m * t)$ & {$[4]$} \\
\hline
\end{tabular}

close to the unit. In this particular work, the correlation coefficient is 0.99 for the Sikame Tagne et al. model.

The model of Sikame Tagne et al. (2014) is the one which has better statistical parameters for the sampling zones. This model is used for the modelling of the absorption kinetics in the twelve sampling zones of the stem of Raffia vinifera. The average parameters of this model are provided in Table 5, the coefficient of linear correlation, the square root of the mean error, and the squared sum of errors of the Raffia vinifera stem.

It can be noticed from Table 5 that the correlation coefficient is always more than 0.98 and remains higher than the obtained values for the other models in Table 4 . Then, we can say that the model of Sikame Tagne [4] is the one which enables the modelling of the experimental data and is illustrated by Figure 6.

It can be concluded that the mathematical equation which enables the description of the water absorption kinetics of the pith of Raffia vinifera from the stem is given by

$$
g(t)=c-a * \exp (-k * t)-b * \exp (-m * t)
$$

where $a, b$, and $c$ are constants and $k$ and $m$ are the diffusion parameters expressed per minutes.

3.4. Determination of the Effective Diffusion Coefficient. The determination of the water diffusion coefficient through the pith of Raffia vinifera is done by using Fick's dual stage law. It was used in the prediction and interpretation of mass transfer through natural fibers $[4,36]$. This method is based on Fick's law and introduces two effective diffusion coefficients $D_{1 \text { eff }}$ and $D_{2 \text { eff }}$ and two water saturation levels corresponding to the two diffusion coefficients. The use of this method on water absorption kinetics for the pith of Raffia vinifera is done by (12) which described two phases of diffusion, that is, an initial and a final stage. The sum of the two saturation levels of the two phases gave the total absorption rate of the pith of Raffia

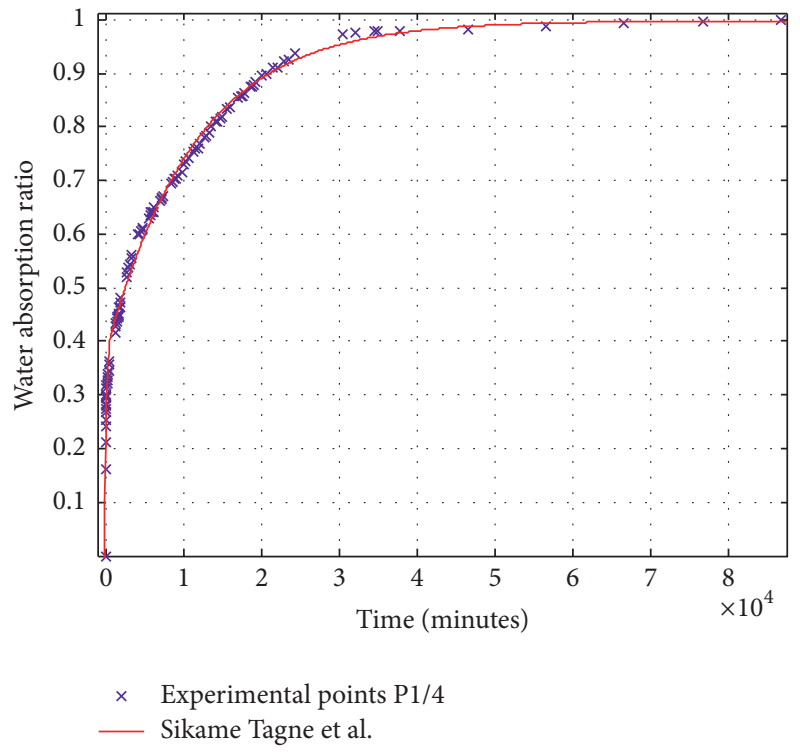

FIgURE 6: Experimental points and model of Sikame Tagne [4] of the pith of Raffia vinifera from the center of the base.

vinifera. The effective diffusion coefficient will be determined by using (12):

$$
\begin{aligned}
M_{t} & =M_{\infty 1}[1 \\
& \left.-\sum_{0}^{+\infty} \frac{8}{(2 n+1)^{2} \pi^{2}} \exp \left(-\frac{D_{1 \mathrm{eff}}(2 n+1)^{2} \pi^{2}}{4 e^{2}} t\right)\right] \\
& +M_{\infty 2}[1 \\
& \left.-\sum_{0}^{+\infty} \frac{8}{(2 n+1)^{2} \pi^{2}} \exp \left(-\frac{D_{2 \mathrm{eff}}(2 n+1)^{2} \pi^{2}}{4 e^{2}} t\right)\right] \\
M_{\infty} & =M_{\infty 1}+M_{\infty 2} .
\end{aligned}
$$




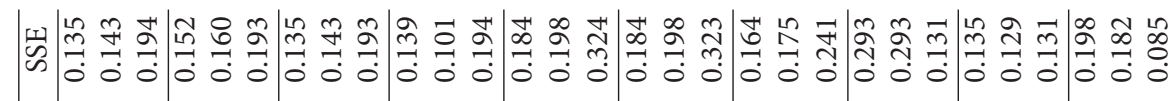

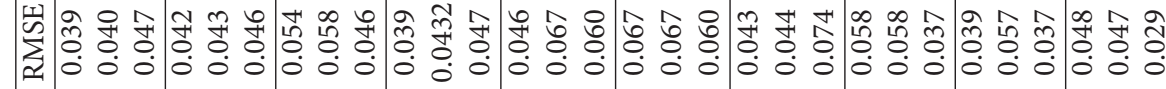

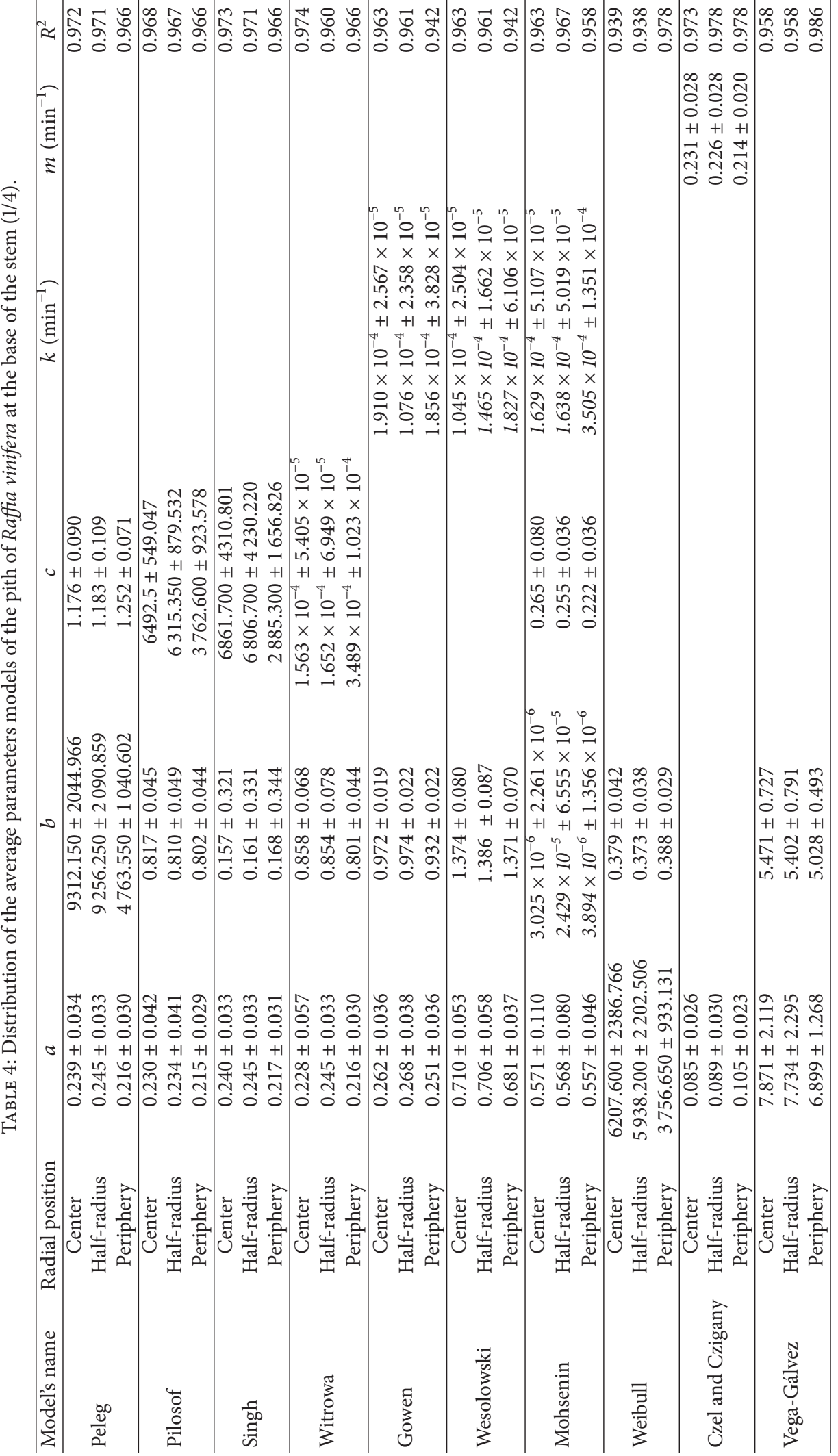




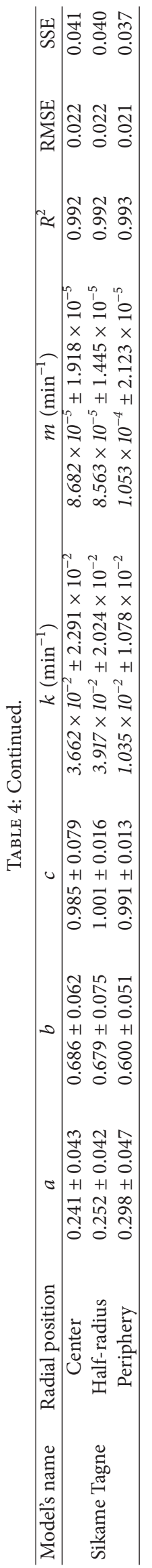




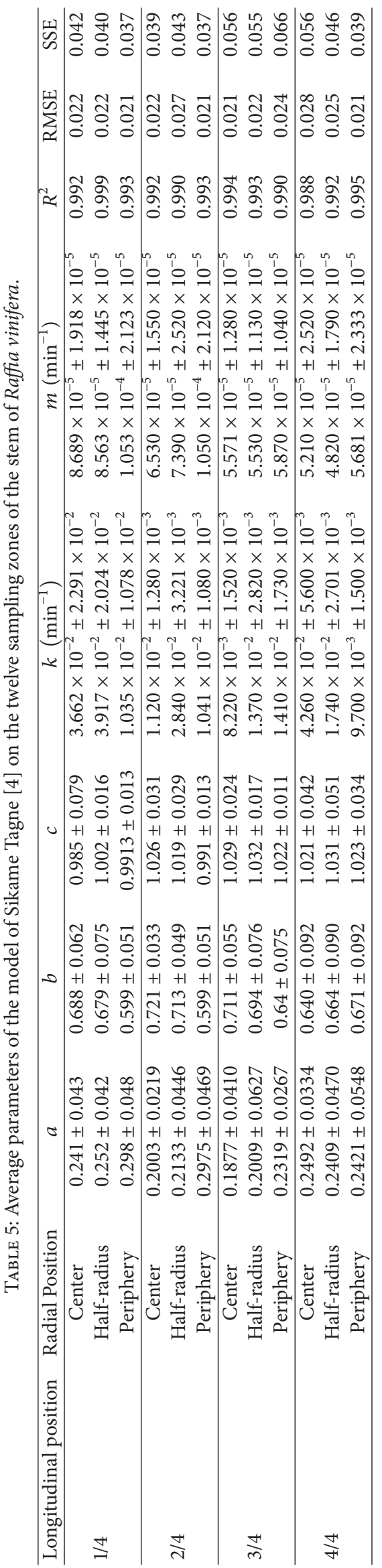




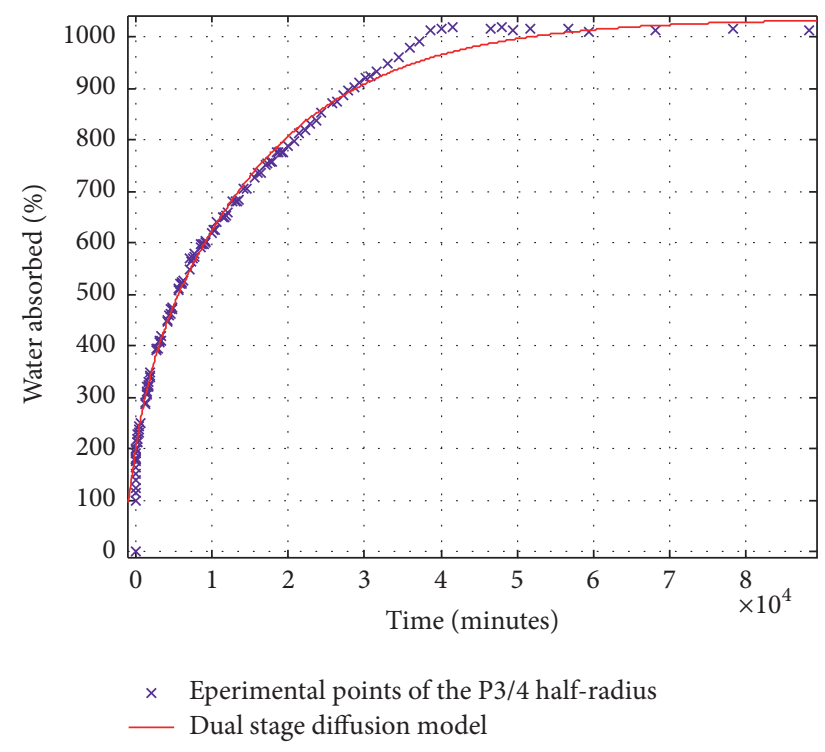

Figure 7: Curves of the water absorption rate and the two-phase diffusion model in part 3/4 in the half-radius zone.

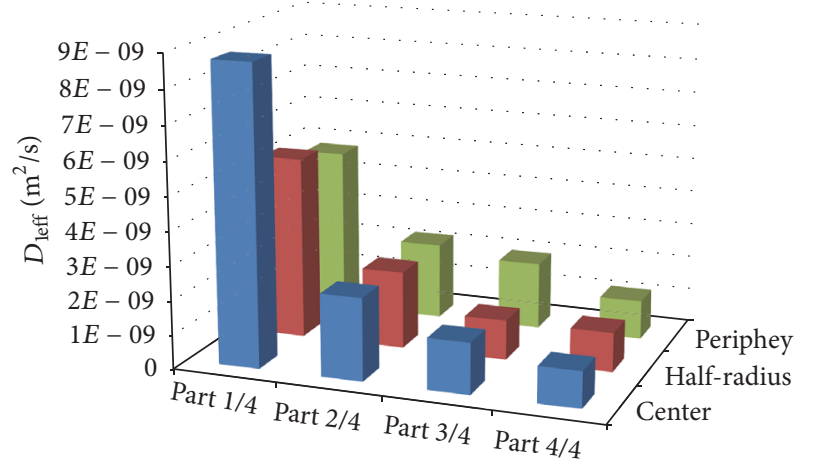

FIgURE 8: Distribution of the effective diffusion coefficient in the pith of Raffia vinifera in twelve sampling zones during the initial stage.

The parameters of this equation are determined in the software environment Matlab 2009b by using experimental data of water absorption $M_{t}$ depending on the time. $D_{\text {leff }}$ and $D_{2 \text { eff }}$ are the respective values of the diffusion coefficient, respectively, at the initial and final phases. $M_{\mathrm{\infty} 1}$ and $M_{\mathrm{\infty} 2}$ are the respective water saturation levels at the initial and final stages.

Experimental data and the curve corresponding to the Fick dual stage formula are presented in Figure 7. An observation of this figure shows that the dual stage saturation method that experimented with Fick's law equation result is the better approach of experimental data.

This work has been done on twelve sampling zones and permits us to obtain the distribution of the effective diffusion coefficient of water in the pith of Raffia vinifera. Those distributions are presented in Figures 8 and 9.

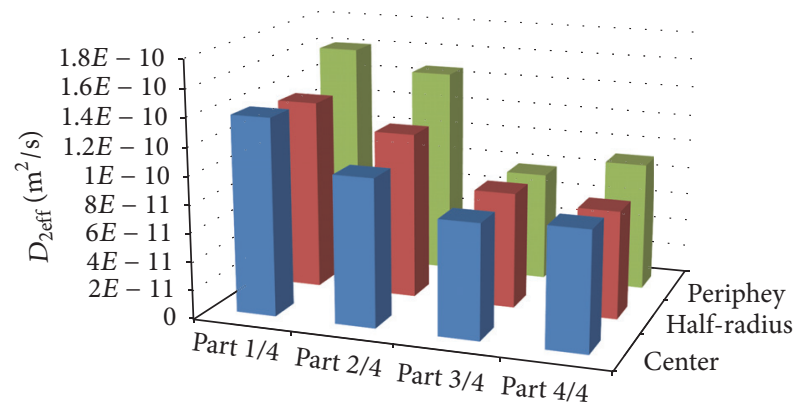

FIGURE 9: Distribution of the effective diffusion coefficient in the pith of Raffia vinifera in twelve sampling zone during the final stage.

Table 6 provides the effective diffusion coefficient, the water absorption rate, and the correlation coefficient in the twelve sampling zones.

The analysis of Table 6 enables us to see that the correlation coefficient of the pith of Raffia vinifera resulting from the modelling of the dual stage of the second law of Fick is higher than 0.98 . This table also shows that the effective diffusion coefficient in the pith of Raffia vinifera increase from $1.063 \times 10^{-9}$ to $8.746 \times 10^{-9} \mathrm{~m}^{2} / \mathrm{s}$ in the initial stage and from $7.668 \times 10^{-11}$ to $1.615 \times 10^{-10} \mathrm{~m}^{2} / \mathrm{s}$ in the second or final stage. Globally, the effective diffusion coefficient decreases from the periphery to the center in the radial position and from part $1 / 4$ to part $4 / 4$ in the longitudinal position in the first part or initial stage. In the second stage, the effective diffusion coefficient has the same trend such as the initial stage. The values of the effective diffusion coefficient obtained in this work are in the same greatness order of certain vegetal species such as the sisal fiber, the jute fiber, the flax fiber, the hemp fiber [36], and the raffia fiber [4].

\section{Conclusion}

This work whose objective is the study of water absorption phenomenon through the pith of Raffia vinifera consisted of the determination of the rate of water absorption. The modelling of the water absorption kinetics and the determination of the effective diffusion coefficient in the twelve sampling zones of the pith of Raffia vinifera were also the objective of this work. The procedure consisted of the immersion of the sample in the distilled water at the constant and room temperature of $30^{\circ} \mathrm{C} \pm 1^{\circ} \mathrm{C}$ and weighing the samples in the regular time intervals. This water absorption rate has values between $392.044 \% \pm 36.618 \%$ and $1331.956 \% \pm 49.144 \%$. We have noticed that the percentage of water absorption of the pith of Raffia vinifera increases from the periphery to the center in the radial position and from the base (part $1 / 4$ ) to the leaves (part 4/4) in the longitudinal position. The modelling of the water absorption kinetics was done by eleven models and the model of Sikame Tagne et al. (2014) gives better statistical parameters with the experimental data. The determination of the diffusion coefficient is done by Fick's second law in the dual stage. The values of the diffusion coefficient increase from $1.063 \times 10^{-9}$ to $8.746 \times 10^{-9} \mathrm{~m}^{2} / \mathrm{s}$ 
TABLE 6: Effective diffusion coefficient of water of the pith of Raffia vinifera during the initial and final stage.

\begin{tabular}{|c|c|c|c|c|c|}
\hline Longitudinal position & Radial position & $D_{1 \text { eff }}\left(\mathrm{m}^{2} / \mathrm{s}\right) \times 10^{-9}$ & $D_{2 \text { eff }}\left(\mathrm{m}^{2} / \mathrm{s}\right) \times 10^{-11}$ & $M_{\infty}$ & $R^{2}$ \\
\hline \multirow{3}{*}{ Part $1 / 4$} & Center & 8.746 & 14.00 & 1148.800 & 0.988 \\
\hline & Half-radius & 5.337 & 13.55 & 790.455 & 0.987 \\
\hline & Periphery & 4.808 & 16.16 & 367.719 & 0.985 \\
\hline \multirow{3}{*}{ Part 2/4 } & Center & 2.415 & 10.48 & 1304.794 & 0.985 \\
\hline & Half-radius & 2.260 & 11.83 & 1163.629 & 0.986 \\
\hline & Periphery & 2.242 & 14.78 & 585.027 & 0.986 \\
\hline \multirow{3}{*}{ Part 3/4 } & Center & 1.493 & 8.130 & 1477.300 & 0.990 \\
\hline & Half-radius & 1.163 & 8.234 & 1219.823 & 0.991 \\
\hline & Periphery & 1.966 & 7.792 & 557.978 & 0.991 \\
\hline \multirow{3}{*}{ Part $4 / 4$} & Center & 1.063 & 8.438 & 1414.600 & 0.990 \\
\hline & Half-radius & 1.150 & 7.668 & 1149.307 & 0.989 \\
\hline & Periphery & 1.149 & 9.159 & 646.913 & 0.988 \\
\hline
\end{tabular}

in the initial stage and from $7.668 \times 10^{-11}$ to $1.615 \times$ $10^{-10} \mathrm{~m}^{2} / \mathrm{s}$. Globally, the diffusion coefficient decreases from the periphery to the center in the radial position and from part $1 / 4$ to part $4 / 4$ in the longitudinal position. This is done in the initial stage and final stage.

\section{Competing Interests}

The authors declare that they do not have any competing interests in this manuscript.

\section{Acknowledgments}

The authors acknowledge the Deputy Director of the Advanced Teachers Training College of University of Douala and the Head of Laboratory who permit this work to take place.

\section{References}

[1] F. I. Obahiagbo, "A review of the origin, morphology, cultivation, economic products, health and physiological implications of raphia palm," African Journal of Food Sciences, vol. 3, no. 13, pp. 447-453, 2009.

[2] R. Musset, "Le raphia," Annale de Géographie, vol. 42, no. 236, pp. 190-193, 1933.

[3] M. Sandy and L. Bacon, "Tensile testing of raffia," Journal of Materials Science Letters, vol. 20, no. 6, pp. 529-530, 2001.

[4] N. R. Sikame Tagne, E. Njeugna, M. Fogue, J.-Y. Drean, A. Nzeukou, and D. Fokwa, "Study of water absorption in raffia vinifera fibres from Bandjoun, Cameroon," The Scientific World Journal, vol. 2014, Article ID 912380, 11 pages, 2014.

[5] S. E. Etuk, L. E. Akpabio, and K. E. Akpabio, "Investigation of Raphia hookeri trunk as a potential ceiling material for passively cooled building design," Ghana Journal of Science, vol. 43, pp. 37,2003.

[6] T. Nganya, Intérêt de l'utilisation des isolants locaux dans l'habitat au Cameroun [Ph.D. thesis], Énergétique, Université de Yaoundé I École Nationale Supérieure Polytechnique, Yaoundé, Cameroon, 2000.
[7] C. K. Kankam, "Raffia palm-reinforced concrete beams," Materials and Structures/Materiaux et Constructions, vol. 30, no. 199, pp. 313-316, 1997.

[8] R. G. Elenga, G. F. Dirras, J. Goma Maniongui, P. Djemia, and M. P. Biget, "On the microstructure and physical properties of untreated raffia textilis fiber," Composites Part A: Applied Science and Manufacturing, vol. 40, no. 4, pp. 418-422, 2009.

[9] R. G. Elenga, G. F. Dirras, J. G. Maniongui, and B. Mabiala, "Thin-layer drying of Raffia textilis fiber," BioResources, vol. 6, no. 4, pp. 4135-4144, 2011.

[10] P. K. Talla, A. Foudjet, and M. Fogue, "Statistical model of strength in compression of Raphia vinifera L. (Arecacea)," Journal of Bamboo and Rattan, vol. 3, no. 3, pp. 229-235, 2004.

[11] P. K. Talla, A. Foudjet, and M. Fogue, "Statistical model of strength in flexion and size effect on the failure of Raphia vinifera L. (Arecacea)," Journal of Bamboo and Rattan, vol. 4, no. 4, pp. 335-342, 2005.

[12] P. K. Talla, T. Tekougnening, J. R. Tangka, E. Ebale, and A. Foudjet, "Nonlinear creep Behaviour of raffia vinifera L. (Arecacea)," International Journal of Mechanics and Solids, vol. 2, no. 1, pp. 1-11, 2007.

[13] P. K. Talla, A. Fomethe, M. Fogue, A. Foudjet, and G. N. Bawe, "Time temperature equivalency of raphia vinifera L. (Arecacea) under compression," International Journal of Mechanics and Solids, vol. 5, no. 1, pp. 27-33, 2010.

[14] R. S. Odera, O. D. Onukwuli, and E. C. Osoka, “Tensile and compressive strength characteristics of raffia palm fibre-cement composites," Journal of Emerging Trends in Engineering and Applied Sciences (JETEAS), vol. 2, no. 2, pp. 231-234, 2011.

[15] N. R. Sikame Tagne, E. Njeugna, M. Fogue, J. Y. Drean, and D. Fokwa, "Study of water diffusion through raffia Vinifera fibres of the stem from bandjoun-cameroon: case of drying kinetics," Research Journal of Applied Sciences, Engineering and Technology, vol. 6, no. 19, pp. 3547-3558, 2013.

[16] J. Khazaei, "Water absorption Characteristics of three Wood varieties," Cercetari Agronomie in Moldova, vol. 41, no. 2, pp. 134-145, 2008.

[17] D. Saikia, "Studies of water absorption behavior of plant fibers at different temperatures," International Journal of Thermophysics, vol. 31, no. 4-5, pp. 1020-1026, 2010.

[18] A. M. R. Pilosof, R. Boquet, and G. B. Batholomai, "Kinetics of water Uptake to Food Powders," Journal of Food Science, vol. 50, no. 1, pp. 1538-1541, 1987. 
[19] N. M. Mohsenin, Physical Properties of Plant and Animal Material, Gordon and Breach Science Publishers, New York, NY, USA, 2nd edition, 1986.

[20] B. P. N. Singh and S. P. Kulshrestha, "Kinetics of water sorption by soybean and pigeonpea grains," Journal of Food Science, vol. 52, no. 6, pp. 1538-1541, 1987.

[21] M. Peleg, "An empirical model for the description of moisture sorption curves," Journal of Food Science, vol. 53, no. 4, pp. 12161217, 1988.

[22] M. Turhan, S. Sayar, and S. Gunasekaran, "Application of Peleg model to study water absorption in chickpea during soaking," Journal of Food Engineering, vol. 53, no. 2, pp. 153-159, 2002.

[23] P. García-Pascual, N. Sanjuán, R. Melis, and A. Mulet, "Morchella esculenta (morel) rehydration process modelling," Journal of Food Engineering, vol. 72, no. 4, pp. 346-353, 2006.

[24] A. Gowen, N. Abu-Ghannam, J. Frias, and J. Oliveira, "Modelling the water absorption process in chickpeas (Cicer arietinum L.) - the effect of blanching pre-treatment on water intake and texture kinetics," Journal of Food Engineering, vol. 78, no. 3, pp. 810-819, 2007.

[25] G. Czel and T. Czigany, "A study of water absorption and mechanical properties of glass fiber/polyester composite pipes-effects of specimen geometry and preparation," Journal of Composite Materials, vol. 42, no. 26, pp. 2815-2827, 2008.

[26] A. Vega-Gálvez, E. Notte-Cuello, R. Lemus-Mondaca, L. Zura, and M. Miranda, "Mathematical modelling of mass transfer during rehydration process of Aloe vera (Aloe barbadensis Miller)," Food and Bioproducts Processing, vol. 87, no. 4, pp. 254260, 2009.

[27] K. Gornicki, A. Kaleta, R. Winiczenko, A. Chojnacka, and M. Janaszek, InTech open science and open Acces, 431-456, 2013.

[28] T. J. Afolabi, S. E. Agary, and T. Y. Tunde-Akintunde, "Modeling the water absorption characteristics of different maize (Zea Mays L.) types during soaking," Chemical and Process Engineering Research, vol. 25, pp. 53-67, 2014.

[29] P. García-Pascual, N. Sanjuán, J. Bon, J. E. Carreres, and A. Mulet, "Rehydration process of Boletus edulis mushroom: characteristics and modelling," Journal of the Science of Food and Agriculture, vol. 85, no. 8, pp. 1397-1404, 2005.

[30] H. Kim and K. Takemura, "Influence of water absorption on creep behaviour of carbon fiber/epoxy laminates," Procedia Engineering, vol. 10, pp. 2731-2736, 2011.

[31] A. Salimi hizaji, Y. Maghsoudlou, and S. M. Jafari, "Application of peleg model to study effect of water temperature and storage time on rehydration kinetics of air dried potato cubes," Latin American Applied Research, vol. 40, no. 40, pp. 131-136, 2010.

[32] A. Salimi Hizaji, Y. Maghsoudlou, and S. M. Jafari, "Effect of water temperature, variety and shelf life on rehydration kinetics of microwave dried potato cubes," Latin American Applied Research, vol. 41, no. 3, pp. 249-254, 2011.

[33] J. Crank, The Mathematics of Diffusion, Oxford University Press, New York, NY, USA, 2nd edition, 1975.

[34] X. J. Fan, S. W. R. Lee, and Q. Han, "Experimental investigations and model study of moisture behaviors in polymeric materials," Microelectronics Reliability, vol. 49, no. 8, pp. 861-871, 2009.

[35] F. Seyhan-Gurtas, M. Mehmet Ak, and E. O. Evranuz, "Water diffusion coefficients of selected legumes grown in Turkey as affected by temperature and variety," Turkish Journal of Agriculture and Forestry, vol. 25, no. 5, pp. 297-304, 2001.

[36] A. Célino, S. Fréour, F. Jacquemin, and P. Casari, "Characterization and modeling of the moisture diffusion behavior of natural fibers," Journal of Applied Polymer Science, vol. 130, no. 1, pp. 297-306, 2013.

[37] A. Addo and A. Bart-Plange, "Kinetics of water sorption by egusi melon (Cucumeropsis edulis) seeds," Journal of Agricultural and Biological Science, vol. 4, no. 6, pp. 14-18, 2009. 

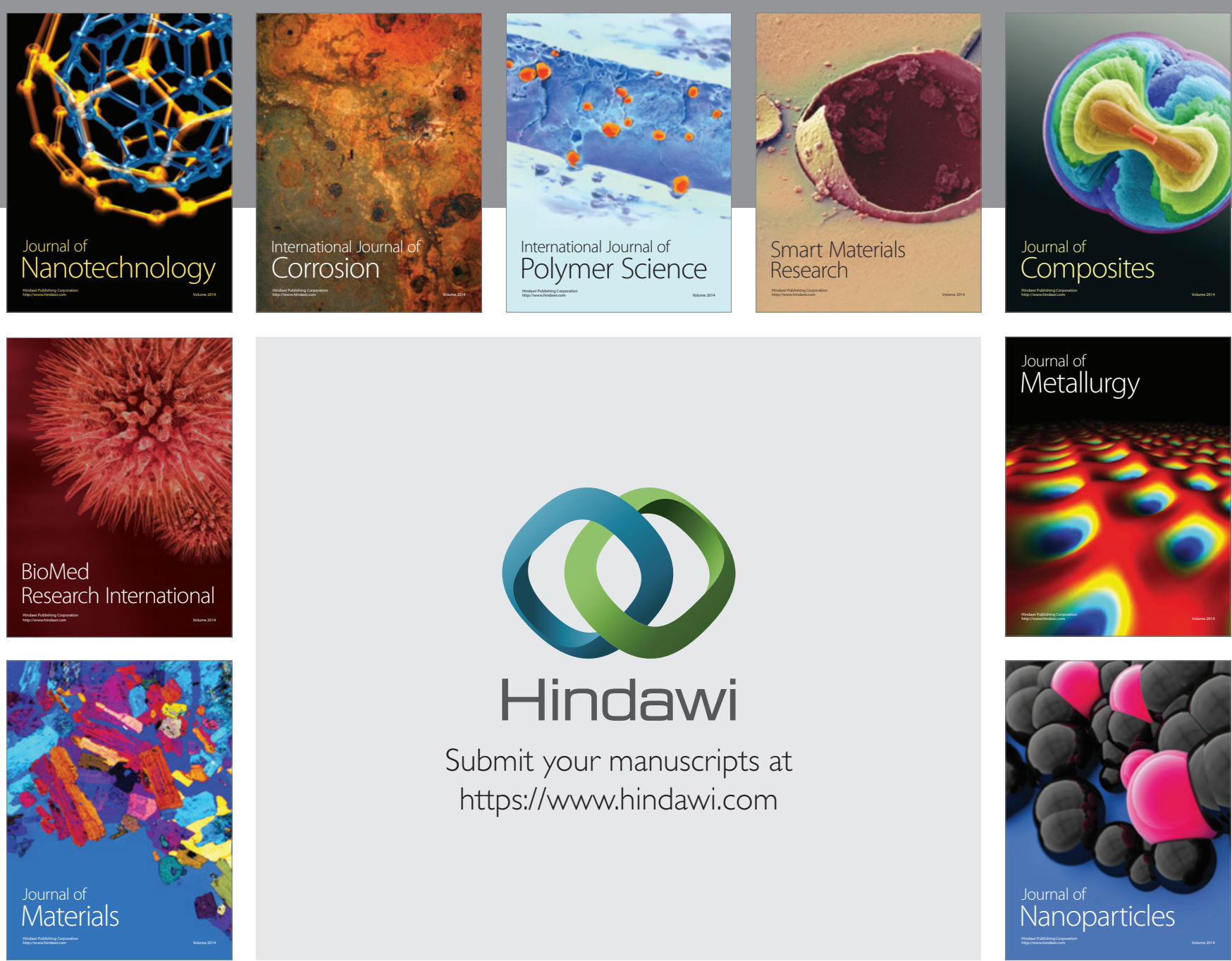

\section{Hindawi}

Submit your manuscripts at

https://www.hindawi.com

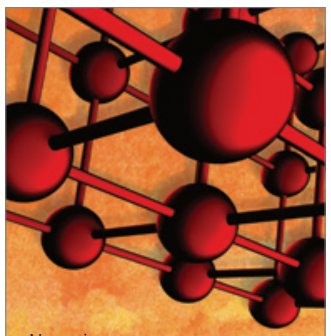

Materials Science and Engineering
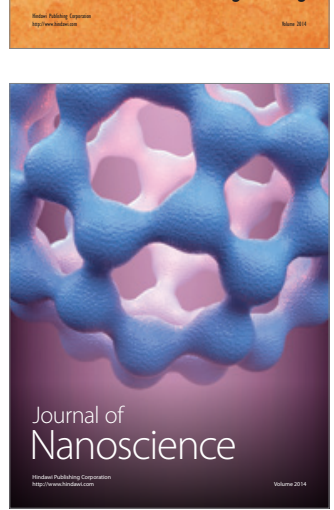
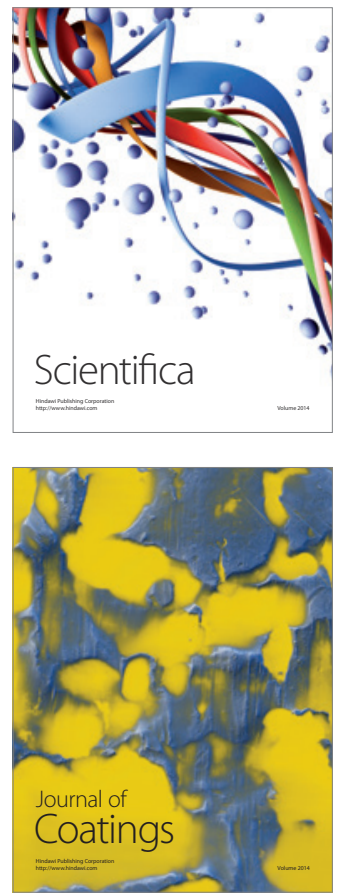
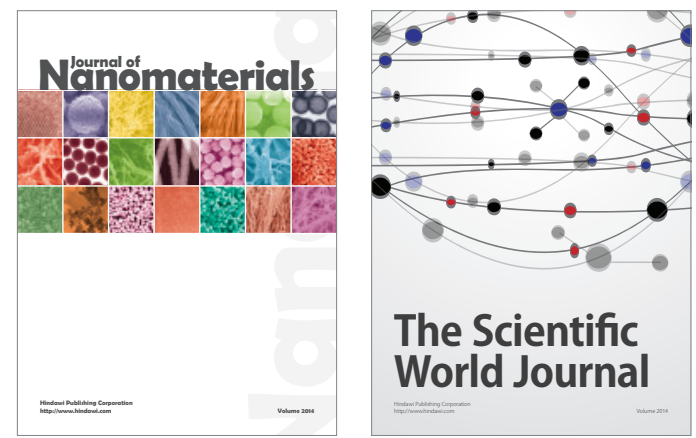

The Scientific World Journal
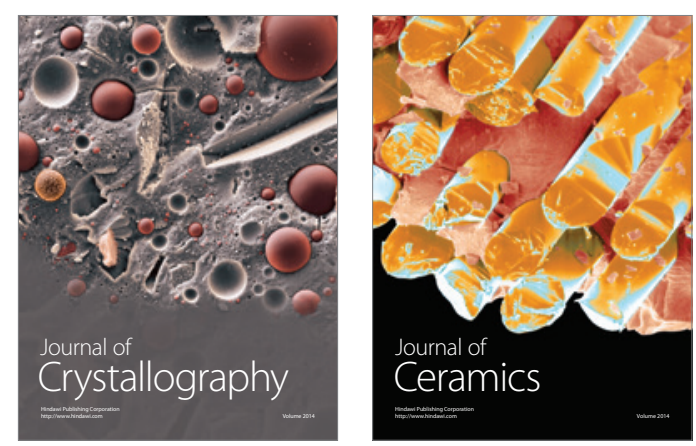
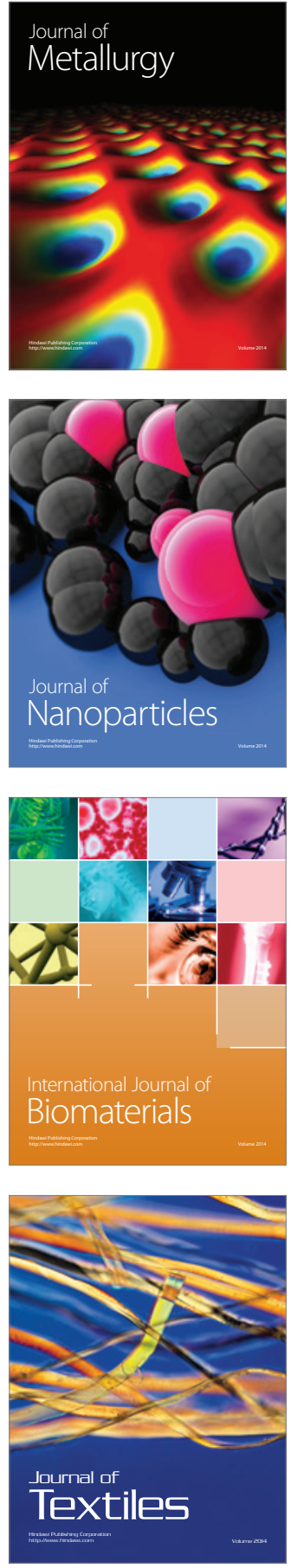